\title{
Back to Briquet and Charcot
}

To the Editor:

April 11, 2008

In March 1996, a 51-year-old man was urgently admitted to the hospital due to left-sided neurologic symptoms. The patient experienced clumsiness and muscle weakness in the left upper and lower limbs. The patient had been well earlier, but during the preceding year his left eye had been examined by an ophthalmologist because of feeling of pressure and ache, but no significant findings emerged. Two weeks earlier, the patient had experienced nausea and feeling of pressure on the forehead.

Upon neurologic examination, diadochokinesis indicated clumsiness on the left side and reflexes were slightly left dominant, but no other abnormal findings were observed. Blood pressure, heart rate, and a 12-lead electrocardiogram were normal. Contrast-enhanced computed tomography scan and magnetic resonance imaging of the brain as well as electroencephalogram and analysis of cerebrospinal fluid were normal. Hematology, electrolytes, blood glucose, and cholesterol levels were within the normal range. The patient was observed for a week and discharged with the diagnosis unclear.

In October 1996, at 52 years of age, the patient attended the psychiatric outpatient ward because of these symptoms. His family history revealed neither psychiatric nor neurologic disorders. The patient stated that 2 years earlier the symptoms of left-sided headache and pain in the neck, upper trunk, and upper limb had started. The psychiatric status of the patient was considered normal. The patient reported various somatic symptoms: altered vision, left-sided facial and neck pain, palpitation, muscle tension, headache, loose stools, feelings of weakness and clumsiness of the left upper and lower limb, urinary urgency, back pain, dermatological problems, dry mouth, leftsided chest pain, tremor, hot and cold waves of body and sweating. The patient appeared to have a lifelong tendency to react to stress with urinary urgency and heart palpitation. The current stress factor was a change in work tasks $\sim 4$ years earlier. We concluded that the patient was suffering from somatization disorder with classical leftside gradient symptoms.

The persistent symptoms implicated further examination. In December 1996, the patient underwent a positron emission tomography

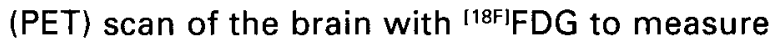
glucose consumption in the brain. In the PET image, prominent glucose consumption in the right putamen as compared with the left was observed. The asymmetry index (side difference as percentage of mean) indicated evident right putamen hypermetabolic gradient $(+10.4 \%)$ in the patient, while a healthy control group $(\mathrm{N}=5$ males, average age: 51 years) had a left-sided gradient (mean: $-3.9 \%$, SD: $4.0 \%$ ). The difference in the asymmetry was $2.57 \mathrm{SD}$, probably reflecting the pathophysiology of the illness (Figure).

The frequency of the somatic symptoms, especially pain, is usually reported more often on the left side than on the right, but they are not associated with sosiodemographic variables. Clinically, the laterality phenomenon is usually reported to be associated with a gradient of leftside somatic symptoms of the body, as seen with this patient. Originally, the idea of predilection of the left side of the body was presented by Pierre Briquet in 1859.1-5

In 1889, Jean-Martin Charcot stated, in dis-

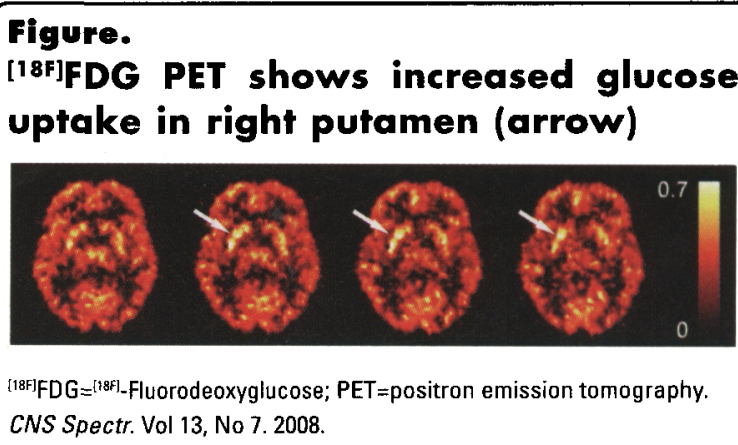


cussing an hysterical upper limb paralysis, "...there is without doubt a lesion of the nervous center.... and which for want of a better term, we designate dynamic or functional lesions." ${ }^{6}$

Recently published data ${ }^{7}$ indicates putaminal activation in patients with conversion disorder, among other brain regions. Additionally, putamen seems to be involved in goal-directed action in a motivational context. ${ }^{8}$

Now, 12 years later, the patient has suffered from various symptoms more or less, but being able to work and he has retired some years ago as planned. No other pathology has occurred during this follow-up period to explain the symptoms.

Sincerely, Mika Hakala, MD

Jussi Hirvonen, MD, PhD

Hasse Karlsson MD, PhD

\section{REFERENCES}

1. Min SK, Lee BO. Laterality in somatization. Psychosom Med. 1997;59:236-240.

2. Axelrod $S$, Noonan $M$, Atanacio $B$. On the laterality of psychogenic somatic symptoms. J Nerv Ment Dis. 1980;168:517-525.

3. Galin D. Diamond R, Braff D. Lateralization of conversion symptoms: more frequent on the left. Am J Psvchiatry. 1977:134:578-580

4. Stern DB. Handedness and the lateral distribution of conversion reaction. J Nerv Ment Dis. 1977;164:122-128
5. Briquet P. Traité de I'hystérie. Paris, France: JB Baillière et Fils; 1859.

6. Charcot JM. Clinical Lectures on Diseases of the Nervous System. vol 2. London, United Kingdom: New Sydenham Society; 1889.

7. Stone J, Zeman A, Simonotto $E$, et al. fMRI in patients with motor conversion symptoms and controls with simulated weakness. Psychosom Med. 2007;69:961-969.

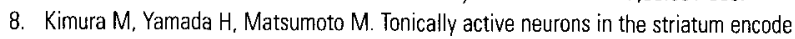
motivational contexts of action. Brain Dev. 2003;25(suppl 1):S20-S23.

Dr. Hakala is senior consultant in the Department of Psychiatry at the University of Turku, in Finland; is Department Chief Psychiatrist at the Harjavalta Psychiatric Hospital, and clinical researcher in the PET Unit at the Turku PET Centre in Finland. Dr. Hirvonen is clinical researcher in the Department of Psychiatry at the University of Turku, and clinical researcher in the PET Unit at the Turku PET Centre. Dr. Karlsson is senior researcher in the PET Unit at the Turku PET Centre in Finland and professor in the Department of Psychiatry at the University of Helsinki in Finland.

Disclosures: Dr. Hakala is an advisor to Janssen-Cilag. Drs. Hirvonen and Karlsson do not have an affiliation with or financial interest in any organization that might pose a conflict of interest.

Please send letters to the editor to: CNS Spectrums, c/o Eric Hollander, MD, 333 Hudson St., 7th Floor, New York, NY 10013; E-mail: vi@mblcommunications.com.

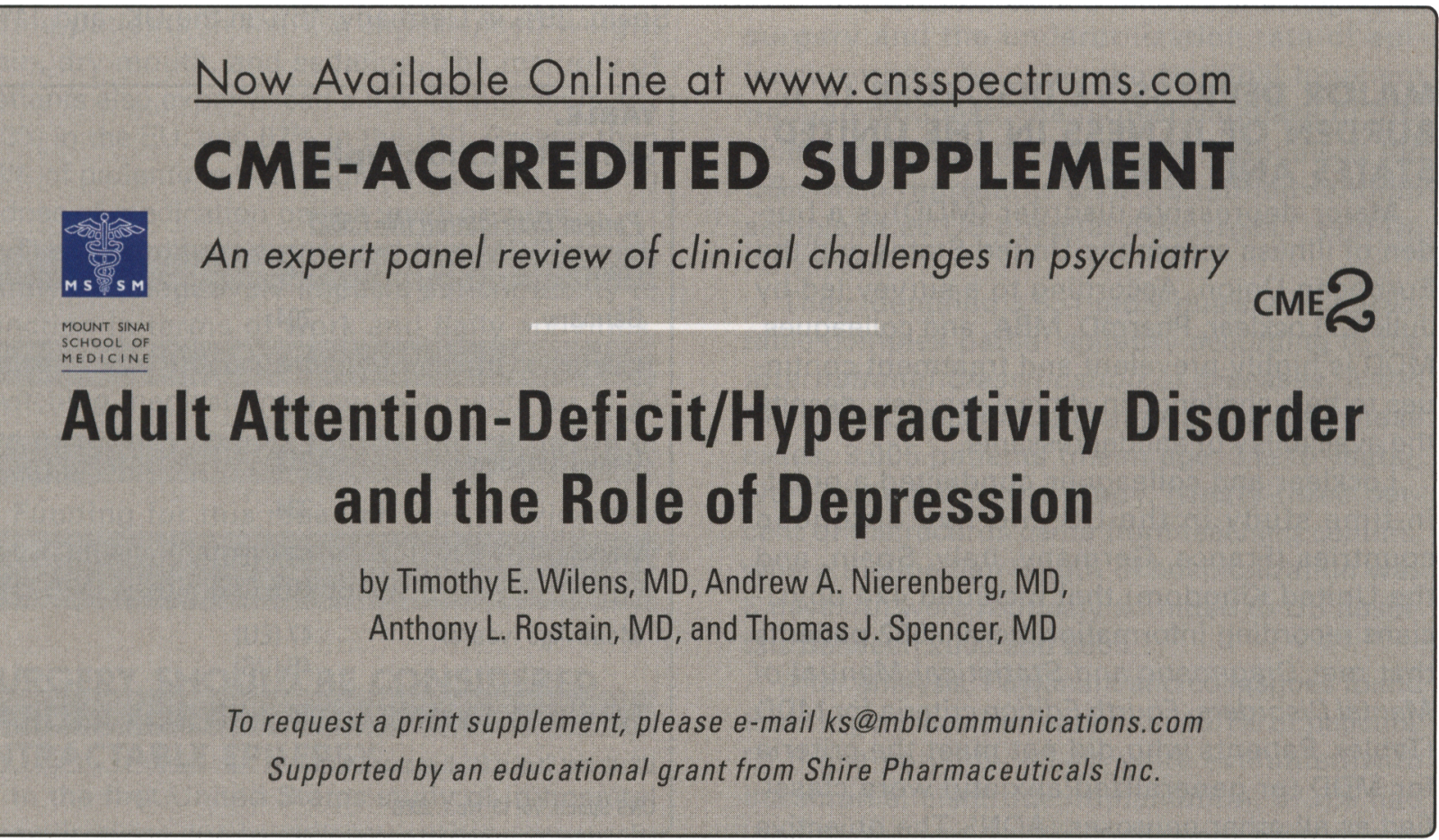

